Supplement of Saf. Nucl. Waste Disposal, 1, 131-132, 2021

https://doi.org/10.5194/sand-1-131-2021-supplement

(C) Author(s) 2021. CC BY 4.0 License.

(c) (i)

Supplement of

\title{
Deformation mechanisms and their microstructural indicators in the compaction of crushed salt as a geotechnical barrier
}

\author{
Kristoff Svensson et al. \\ Correspondence to: Kristoff Svensson (kristoff.svensson@bgr.de)
}

The copyright of individual parts of the supplement might differ from the article licence. 


\title{
Deformation mechanisms in the compaction of crushed salt
} as geotechnical barrier

\author{
Kristoff Svensson ${ }^{1}$, Kornelia Zemke ${ }^{1}$, Ben Laurich ${ }^{1}$
}

${ }^{1}$ Federal Institute for Geosciences and Natural Resources, Stilleweg 2, 30655 Hannover, Deutschland

\section{Introduction}

2021 Nov., 10. -12 .
Interdisciplinary research symposium
on the safety of nuclear disposal practices

Crushed salt is considered as the most suitable backfill material in the disposal of radioactive waste within salt formations [1]. Its rheology is controlled by the allocation of different deformation mechanisms, which, in turn, are controlled foremost by moisture, temperature and deformation state as well as deformation rate [2, 3, 4].

Therefore, we investigated the microstructure of three crushed salt samples that differ in moisture content $(0.1-0.3 \mathrm{Wt} . \%)$, increasing degree of compaction (loose material, 16 and $6 \%$ remaining porosity), and compaction rate (ranging from $10^{-7}$ to $10^{-10}$ ).

\section{Indicators for deformation mechanisms}

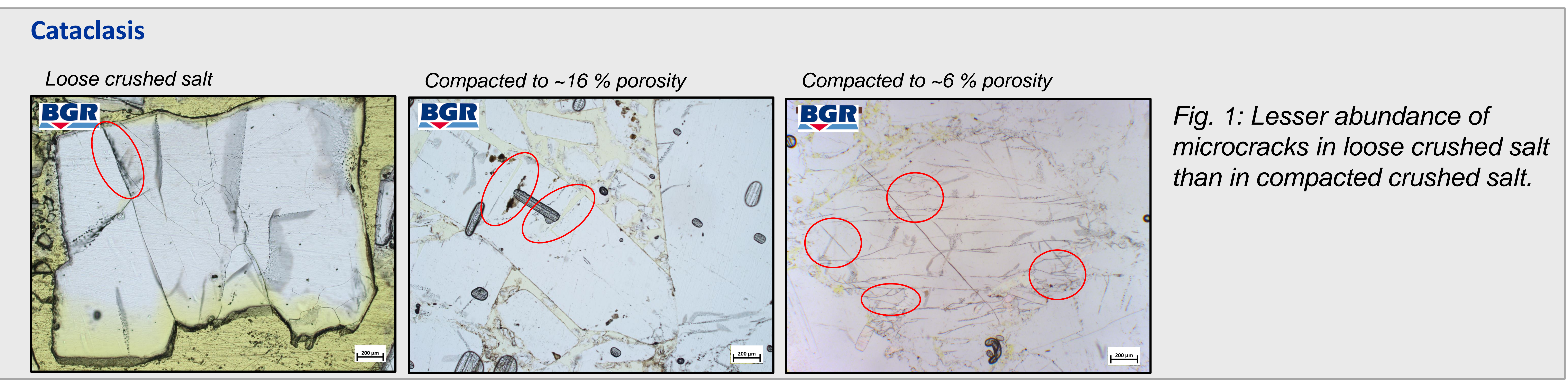

\section{Dislocation creep}
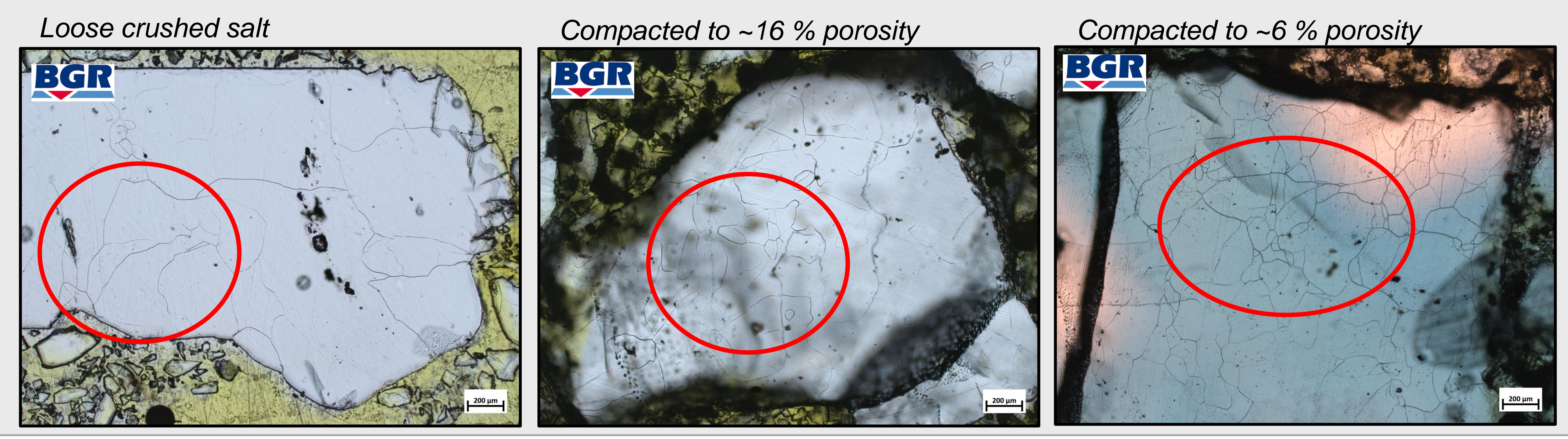

Fig. 2: Number of subgrains (visible as fine lined substructures within solid salt grains) increased, while size decreased with higher compaction.

\section{Solution-precipitation creep}

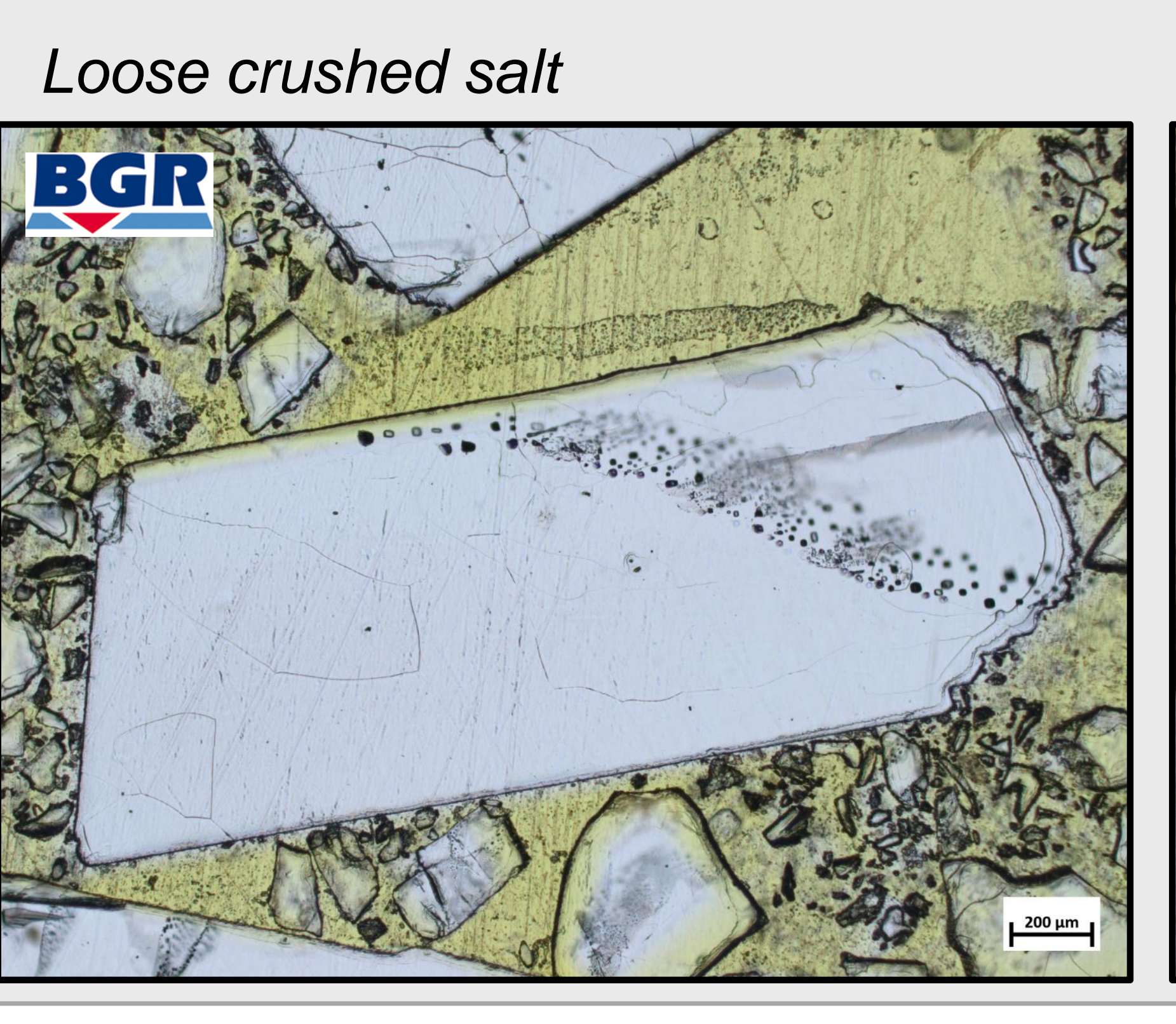

Compacted to $\sim 16 \%$ porosity

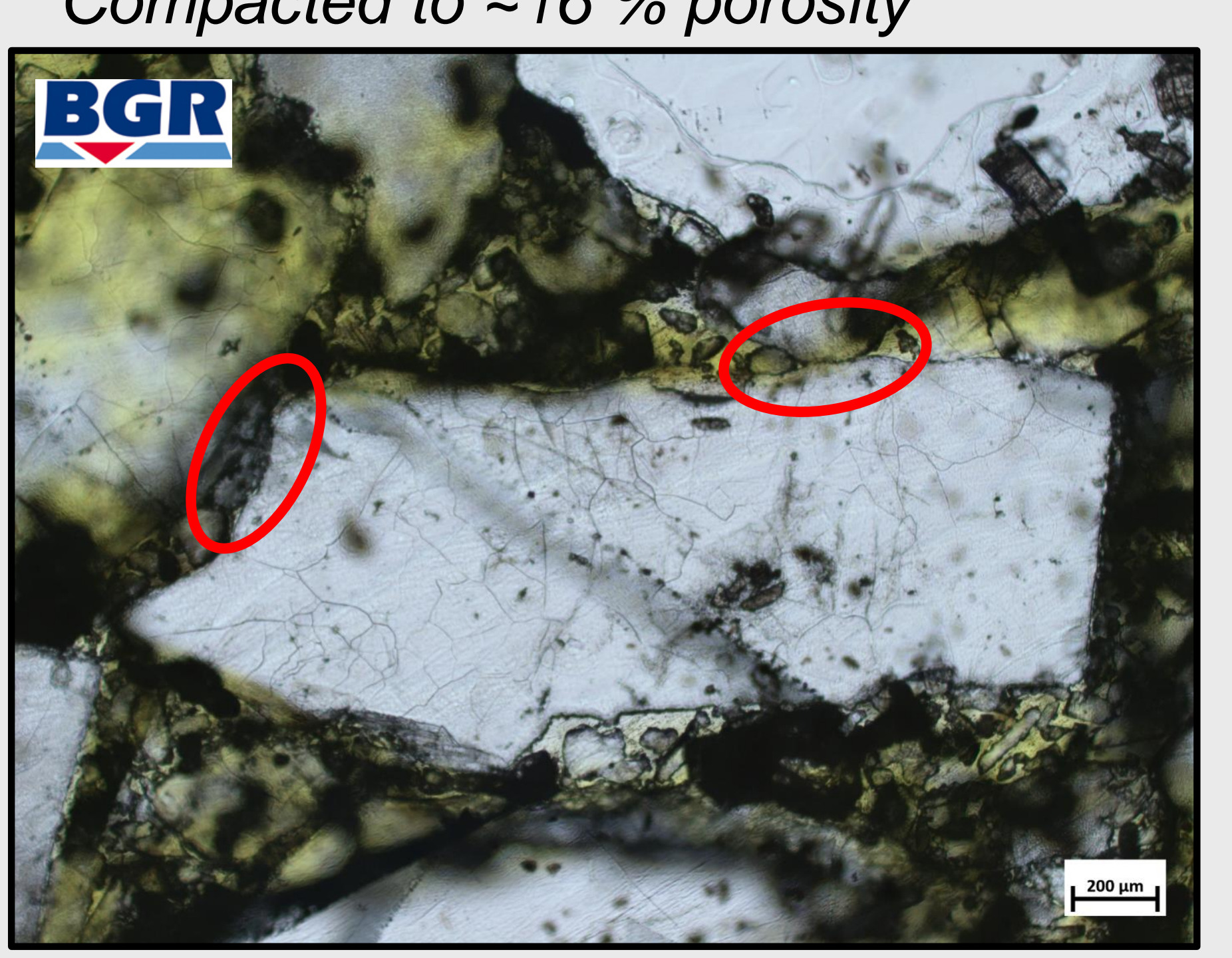

Compacted to $\sim 6 \%$ porosity

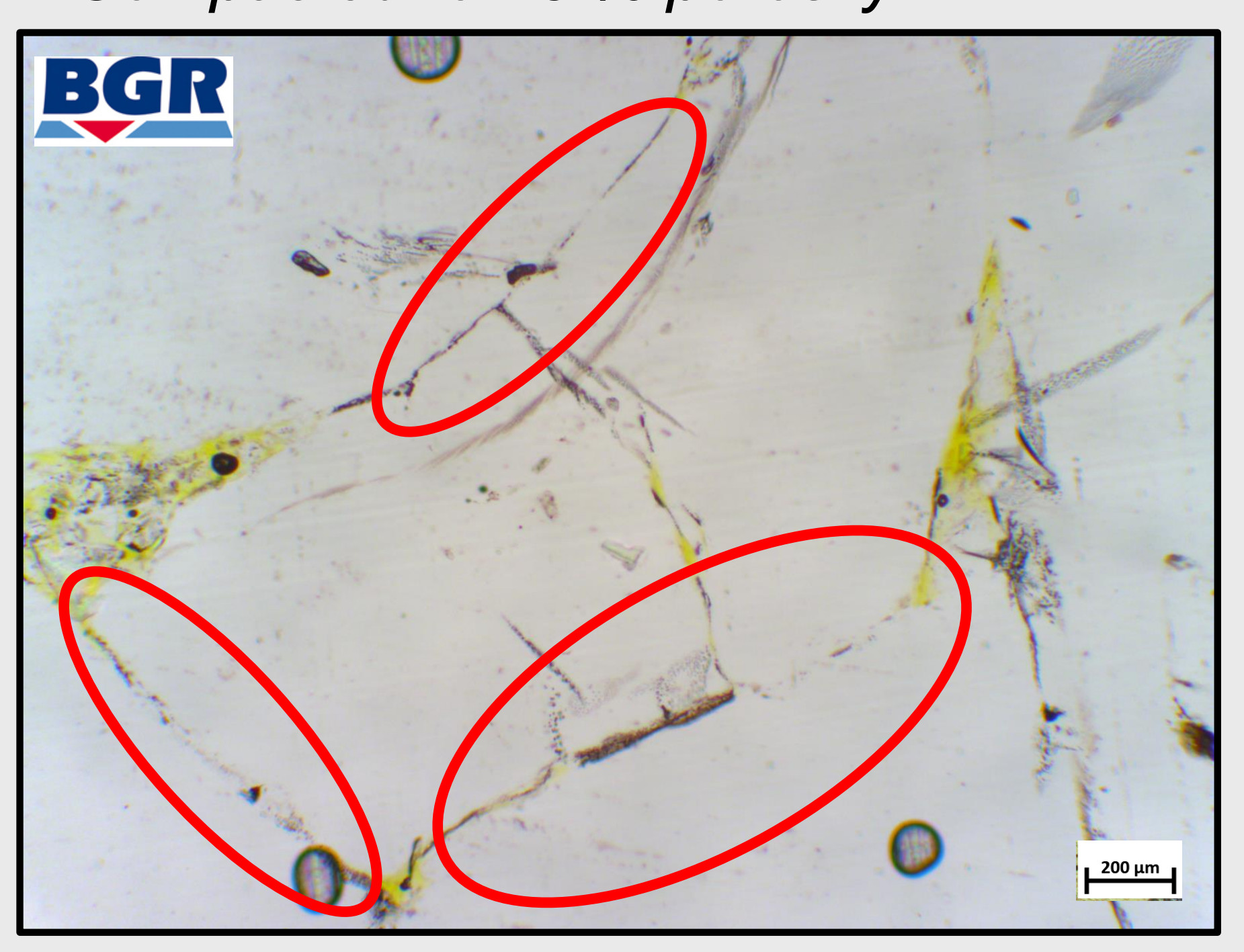

Fig. 3: With increasing degree of compaction, the contact area of grains and the number of rounded grain boundaries increases. This increase is an indicator for pressure solution-precipitation creep.

\section{Preliminary results}

We rank the microstructural deformation indicators (Fig. $1-3$ ) subjectively for their quantity and preliminary conclude:

- All known deformation mechanisms are active at laboratory scale.

- For highly compacted samples, we report more rounded grain boundaries and more subgrains. This indicates visco-plastic deformation by pressure solution-precipitation creep and dislocation creep.

- From looking at the microstructures alone, it was not possible to distinguish the samples original moisture state (0.1 and $0.3 \mathrm{wt} . \%)$.
Outlook:

- Quantitative determination of deformation mechanisms with regard to different environmental settings.

- Comparison of laboratory and in-situ compacted crushed salt.

Literature

[1] Czaikowski, O., Friedenberg, L., Wieczorek, K., Müller-Hoeppe, N., Lerch, C., Eickemeier, R., Laurich, B., Liu, W., Stührenberg, D., Svensson, K., Zemke, K., Lüdeling, C., Popp, T., Bean, J., Mills, M., Reedlunn, B., Düsterloh, U., Lerche, S., and Zhao, J.: Compaction of crushed Salt for the safe containment, KOMPASS - final report, GRS 608, GRS, Braunschweig, Germany, ISBN 978-3947685-94-3, 2020.

[2] Mills, M. M., Stormont, J., and Bauer, S. J.: Micromechanical processes in consolidated granular salt, Engineering Geology, 239, 206-213, doi:10.1016/j.enggeo.2018.03.024, 2018a.

[3] Blenkinsop, T.: Microstructures and Deformation Mechanisms in Minerals and Rocks, Kluwer Academic Publishers, New York, USA, ISBN: 0-412-73480-X, 2002.

[4] Jackson, M. P. A. and Hudec, M. R.: Salt Tectonics - Principles and Practice, Cambridge University Press, University Printing House, Cambridge, UK, ISBN: 978-1-107-01331-5, 2017. 